\title{
ANÁLISE DO EFEITO DA POROSIDADE NA CONDUTIVIDADE TÉRMICA DE PÓS DE SEMENTES DE CEVADA
}

\author{
M. P. FELIZARDO ${ }^{1 *}$, J. T. FREIRE ${ }^{1}$ \\ ${ }^{1}$ Universidade Federal de São Carlos, Departamento de Engenharia Química \\ *e-mail: mpfelizardo@ufscar.br
}

\begin{abstract}
RESUMO
O estudo da condutividade térmica é importante devido a ser um dos parâmetros que contribui para a compreensão da transferência de calor em meios porosos. A semente de cevada tem ampla aplicação nos setores alimentícios, onde nestes processos industriais, estão incluídos diversos processos de transferência de calor. Com base nisto, o objetivo deste trabalho é a análise do efeito da porosidade sobre a condutividade térmica efetiva do pó das sementes de cevada. A condutividade térmica foi medida por meio do método da fonte de calor contínua linear em regime transiente. Para a estruturação do leito com diferentes porosidades foram utilizadas diferentes técnicas de empacotamento, sendo estes: empacotamento aerado, compactado, comprimido com impactos e comprimido através de uma força aplicada por prensa hidráulica. Obtiveram-se através destes métodos as respectivas porosidades de leito de $0,64 \pm 0,01,0,45 \pm 0,02,0,34 \pm 0,01$ e $0,26 \pm 0,01$. As condutividades térmicas medidas em função das porosidades, demonstraram através das análises de características físicas do leito que a variação da porosidade não apresentou efeito significativo sobre a condutividade térmica efetiva.
\end{abstract}

\section{INTRODUÇÃO}

Os estudos dos fenômenos de transporte em meios porosos são importantes em diversos setores da ciência e tecnologia. A transferência de calor em meios porosos existe em diversas operações unitárias das indústrias químicas e de alimentos, dentre eles podem ser citados: filtração, destilação, secagem, reações em leitos fixos e fluidizados.

Dentre os diversos parâmetros ligados ao estudo da transferência de calor, a condutividade térmica dos meios porosos é um parâmetro fundamental para a maioria dos processos térmicos, sendo destaque no que diz respeito ao dimensionamento de equipamentos quanto à sua otimização e conservação de energia.

Dentre os diversos modos de medida da condutividade térmica, segundo Pietrobon (1988) existem dois tipos de métodos de determinação desse parâmetro, os que são medidos em regime estacionário e os que são medidos em regime transiente.

O método da sonda linear é um método em regime transiente, que consiste em uma fonte de calor linear e contínua imersa num meio infinito, isotrópico e homogêneo.

Segundo Holman (1983), a Equação 1, representa o processo de transferência de calor por condução, em coordenadas cilíndricas e unidirecional em $\mathrm{r}$ (radial). 
$\frac{\partial^{2} T}{\partial r^{2}}=\frac{1}{\alpha} \cdot \frac{\partial T}{\partial t}$

A solução da Equação 1, para o sistema de sonda linear, deve seguir as seguintes hipóteses (CARSLAW e JAEGER, 1959).

- O comprimento da fonte de calor linear deve ser muito maior do que o diâmetro;

- A geração de calor na sonda deve ser constante;

- O meio poroso deve ser uniforme, e

- Devem ser reduzidas ao máximo a convecção e radiação de calor.

Com base nestas hipóteses, as condições de contorno são definidas pelas Equações de 2 a 4 , a seguir.

$$
\mathrm{t}=0 \text { e } \forall \mathrm{r}, \Delta T(r, t)=0
$$

$\mathrm{r}=0$ e $\mathrm{T} \geq 0, \lim _{r \rightarrow 0}\left(r \cdot \frac{\partial T}{\partial r}\right)=-\frac{q}{2 \cdot \pi \cdot k}$

$\mathrm{r} \rightarrow \infty$ e $\mathrm{T} \geq 0, \lim _{r \rightarrow \infty} \Delta T(r, t)=0$

A primeira hipótese garante que, com o comprimento muito maior que o diâmetro a transferência de calor possa ser aproximada como unidirecional, na direção radial.

As condições de contorno foram definidas com base na variação de temperatura, que é $\Delta T(r, t)=T(r, t)-T_{o}$.

Com estas condições de contorno têmse a solução matemática da Equação 1, que tem um termo que consiste em um série infinita com o tempo no denominador. Truncando esta série no primeiro termo, pois tempos longos de experimento estes termos são muito pequenos, tem-se a solução na Equação (5), onde a variação da temperatura na superfície da sonda $(\mathrm{r}=\mathrm{a})$ em função do logaritmo neperiano do tempo é uma função linear.
$\Delta T(a, t)=\frac{q}{4 \cdot \pi \cdot K_{\text {eff }}} \cdot\left[\ln \left(\frac{4 \cdot \alpha}{c \cdot a^{2}}\right)+\ln (t)\right]$

Portanto, a derivação desta solução em In (t) fornece que, através do coeficiente angular da variação de temperatura no centro do leito em função do logaritmo neperiano do tempo, pode ser obtida a condutividade térmica efetiva de um meio poroso, conforme Equação 6.

$$
K_{e f f}=\frac{q}{4 \cdot \pi \cdot(d \Delta T(a, t) / d \ln t)}
$$

Este método foi empregado neste trabalho para o estudo da condutividade térmica da cevada em pó. A cevada consiste em uma semente com ampla aplicação na área de tecnologia de alimentos, sendo a principal matéria-prima da indústria cervejeira em todo o mundo. Onde a compreensão dos parâmetros de transferência de calor e massa é imprescindível para a qualidade do produto final.

Com base nisto, o objetivo deste trabalho é a análise dos efeitos da porosidade na condutividade térmica nas sementes de cevada moídas, através do método de fonte de calor linear constante e em regime transiente.

\section{MATERIAIS E MÉTODOS}

Nesta seção, serão descritos os materiais e métodos utilizados para alcançar o objetivo deste trabalho.

\subsection{Método da Fonte de Calor Linear}

A medida da condutividade térmica efetiva do leito de sementes foi medida através do método da fonte de calor linear. $\mathrm{O}$ sistema experimental para a medida desta propriedade está esquematizado na Figura 1, que consiste de uma sonda (6) composta por uma resistência elétrica isolada, com potência nominal de $600 \mathrm{~W}$ e tensão elétrica de $220 \mathrm{~V}$. 
As dimensões da sonda, de geometria cilíndrica, apresentam $6,4 \mathrm{~mm}$ de diâmetro e $26,5 \mathrm{~cm}$ de comprimento.

Uma fonte elétrica regulada em tensão de $(9,75 \pm 0,15) \mathrm{V}$ e corrente elétrica de 0,13 A, forneceu calor por unidade de comprimento da sonda de $(4,30 \pm 1,29) \mathrm{W} / \mathrm{m}$ por meio de uma resistência elétrica.

Iniciando o fornecimento de calor pela fonte elétrica (1), foi realizada a medida da temperatura na parede da sonda ao longo do tempo de aquecimento, por meio de um termopar, tipo J (5) localizado a uma altura média do leito.

Figura 1 - Esquematização do sistema experimental de sonda linear.

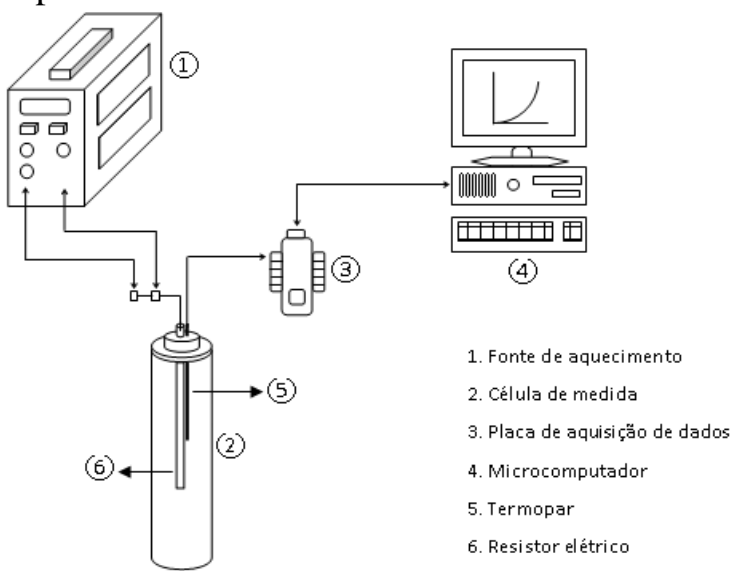

Fonte: Perazzini (2014).

Os dados foram lidos pela placa de aquisição (3) da Personal daq/56 e armazenados por meio de um microcomputador (4).

A célula de medida (2) foi construída em PVC, com uma tampa isolada, para evitar a transferência de calor no sentido longitudinal. A célula apresentava geometria cilíndrica, com diâmetro de $5,08 \mathrm{~cm}$ e altura de $26,5 \mathrm{~cm}$.

A Figura 2 mostra a curva característica da variação da temperatura em função do logaritmo neperiano do tempo.

Observa-se que, a partir destes dados, apenas será considerado o período linear, que corresponde ao período que satisfaz as hipóteses e restrições do modelo. Com base no coeficiente angular desta reta, pode ser estimada a condutividade térmica efetiva por meio da Equação 5.

Figura 2 - Variação da temperatura em função do logaritmo neperiano do tempo.

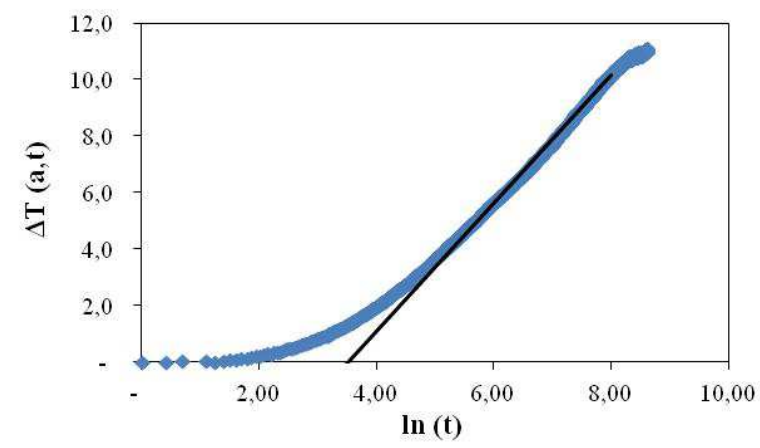

Fonte: Autor (2015).

\subsection{Obtenção do Pó de Sementes de Cevada}

As sementes utilizadas neste trabalho foram obtidas da empresa Agromalte e colhidas no estado do Paraná. Estas sementes foram armazenadas na temperatura de aproximadamente $4^{\circ} \mathrm{C}$ até a sua utilização (CARVALHO; NAKAGAWA, 1980).

Para a limpeza das sementes foi utilizado elutriador da marca De Leo. Para isto, a velocidade foi ajustada, de forma que ocorresse a separação das sementes de materiais, como: palhas, sementes quebradas, folhas, entre outros materiais leves. Por fim, uma seleção mais rigorosa foi realizada manualmente e com o apoio de uma lupa de aumento de dez vezes, com uma lâmpada acoplada.

Este material limpo foi moído em moinho de facas (Stoneware), com malha de orifícios de $1 \mathrm{~mm}$. Antes de o material ser utilizado em experimentos, a homogeneização do pó de cevada foi realizada em quarteador de 18 canais.

\subsection{Testes Preliminares}

Os testes preliminares foram com base na porosidade total do leito. 
As massas específicas reais das sementes de cevada moídas e inteiras foram determinadas através de picnômetro a hélio (AccuPyc 1330 V3.03-Micromeritics).

E para a medida da massa específica do leito utilizou-se a técnica de empacotamento de um leito de partículas em proveta graduada, obtendo a massa específica do leito através da relação de massa e volume.

Inicialmente, aproximadamente $100 \mathrm{~g}$ de partículas foram colocadas na proveta sob a ação da gravidade, despejando de uma altura fixa, com a medida deste volume foi estimada a massa específica do leito aerado.

Logo após, a proveta foi posicionada em um suporte de madeira, onde era possível levantar a proveta até uma altura de aproximadamente $8 \mathrm{~cm}$, limitada por uma placa horizontal, soltando a proveta em condições aproximada a queda livre.

A cada 100 batidas (ou impactos) foi anotado o volume, totalizando 500 batidas. Quando não ocorreu mais a variação do volume, obteve-se o valor de massa específica compactada.

Para avaliar a compressibilidade deste leito compactado, o método de compactação descrito anteriormente foi realizado com as partículas na célula de medida (Figura 1) e com o auxílio de um êmbolo foi realizada a compressão deste meio poroso. Onde a base, de geometria cilíndrica, foi construída em PVC, com $3 \mathrm{~cm}$ de altura e aproximadamente $5 \mathrm{~cm}$ de diâmetro.

Na base de PVC foi acoplado um tubo, com altura de $30 \mathrm{~cm}$, com o diâmetro interno de $6,4 \mathrm{~mm}$. Neste tubo, com o auxílio de uma marreta emborrachada foram aplicados impactos, tomando o cuidado de manter aproximadamente a mesma força em cada impacto. Durante os impactos a base de PVC comprimia a superfície do meio poroso, reduzindo a porosidade.

Para a posterior inserção da sonda no meio poroso, uma guia para manter um espaço suficiente para as dimensões da sonda foi utilizada. Esta guia foi construída em tubo maciço de cobre com altura de $28 \mathrm{~cm}$ e diâmetro de $6 \mathrm{~mm}$.

A utilização de cevada moída para este trabalho foi discutida nos resultados e discussões, com base nos resultados deste estudo.

\subsection{Preparação do Leito}

Para obter diferentes densidades de meio poroso, foram necessárias quatro técnicas diferentes de preparação do leito.

A primeira configuração de leito foi obtida com o empacotamento aerado, ou seja, o pó de sementes foi despejado na célula de medida (Figura 1) de uma altura fixa, tomando cuidado para que não houvesse impactos, evitando assim que o leito reduzisse seu volume inicial.

A segunda configuração de leito foi obtida com o leito compactado, aproximadamente 100 gramas de sementes moídas foram despejadas de uma altura fixa, e então, foram realizados impactos em queda livre, de uma altura de aproximadamente 8 $\mathrm{cm}$, até que o volume não alterasse.

Para a terceira configuração de leito, adicionou-se aproximadamente 125 gramas de sementes moídas na célula de medida (Figura 1), seguindo o mesmo procedimento da segunda configuração e por fim com o auxílio de uma marreta emborrachada eram realizados impactos sobre o eixo do embolo (comentado anteriormente) que compactava o material. Estes impactos foram realizados, até que não houvesse mais redução do volume do leito.

Para a quarta configuração de leito, aproximadamente 135 gramas foram adicionados a célula de medida (Figura 1), seguindo o mesmo procedimento da segunda configuração e a compressão do leito foi realizada por uma prensa hidráulica. Neste processo de compactação aplicou-se a força de 1,5 toneladas. A aplicação da força foi realizada em três ciclos de carga e descarga, 
para possíveis acomodações do material no interior do leito.

Para todas as formas de empacotamento foram adicionadas quantidades de pós de sementes de cevada até o preenchimento total da célula de medida de condutividade térmica.

Os valores de massa referidos anteriormente correspondem a cerca de um quarto da massa total para o preenchimento do leito para cada técnica de empacotamento.

Cada técnica de empacotamento foi repetida três vezes. Para cada repetição foram realizadas três réplicas de medida de condutividade térmica.

Entre as réplicas, os leitos foram mantidos aproximadamente por 18 horas sem fornecimento de calor, para que a condição homogênea de temperatura fosse satisfeita, conforme Equação 2.

Além disto, os testes não ultrapassaram a temperatura de $40^{\circ} \mathrm{C}$ no centro do meio poroso, pois além de evitar danos fisiológicos ao material, buscou-se reduzir a transferência de calor por radiação.

\subsection{Caracterizações do Leito Após a Medida da Condutividade Térmica}

Após a realização dos testes de condutividade térmica foi feita as avaliações de porosidade do leito, umidade e distribuição granulométrica.

A massa específica do leito foi obtida para as três regiões da célula de medida da condutividade térmica: topo, meio e base.

Para realizar as medidas nestas regiões ao longo da altura do leito, uma massa correspondente a um terço do total da massa do leito foi retirada da célula de medida, então com o auxílio de uma régua obteve-se a altura correspondente. Com estes dados, a porosidade total do leito foi calculada por meio da Equação 7.

$\varepsilon_{L}=1-\frac{\rho_{L}}{\rho_{R}}$
A umidade foi determinada pelo método de estufa a $(105 \pm 3)^{\circ} \mathrm{C}$ e balança analítica (precisão de 0,0001). Esta medida foi realizada em triplicata para o topo, meio e base de um mesmo leito.

A umidade em base úmida $\left(X_{\text {b.u. }}\right)$ pode ser calculada conforme Equação 8.

$$
X_{b . u .}=\frac{m_{u}-m_{s}}{m_{u}}
$$

A massa úmida $\left(\mathrm{m}_{\mathrm{u}}\right)$ foi obtida imediatamente após a retirada da amostra do leito e a massa seca $\left(\mathrm{m}_{\mathrm{s}}\right)$ após 24 horas em estufa.

A distribuição granulométrica foi determinada em peneiras de 212, 250, 300 e $355 \mu \mathrm{m}$ de abertura de malha, com 50 gramas de pós de sementes de cevada e amplitude de vibração de $3 \mathrm{~mm}$, durante 30 minutos.

As caracterizações de umidade e de umidade foram feitas para cada um terço de massa retirada da massa total do leito. Essas diferentes partes de massa foram classificadas em topo, meio e base.

\section{RESULTADOS E DISCUSSÕES}

Nesta seção serão apresentados os resultados dos experimentos realizados.

\subsection{Testes Preliminares}

A massa específica real das sementes moídas foi de $(1,44 \pm 0,01) \mathrm{g} / \mathrm{cm}^{3}$ e para as sementes inteiras foi de $(1,25 \pm 0,01) \mathrm{g} / \mathrm{cm}^{3}$.

$\mathrm{Na}$ Figura 3 tem-se a massa específica do leito em função do número de batidas para a compactação das sementes de cevada moídas e inteiras.

Com base na Figura 3 tem-se que, a massa específica do leito de sementes moídas e inteiras de cevada, não apresentaram variações para mais que 200 batidas e 100 batidas, respectivamente.

Pode-se observar que, a redução do tamanho de partículas reduz a escoabilidade de sólidos, sendo necessários mais impactos 
para a compactação do leito de sementes moídas de cevada em relação às inteiras.

Figura 3 - Massa específica do leito em função das batidas para compactação.

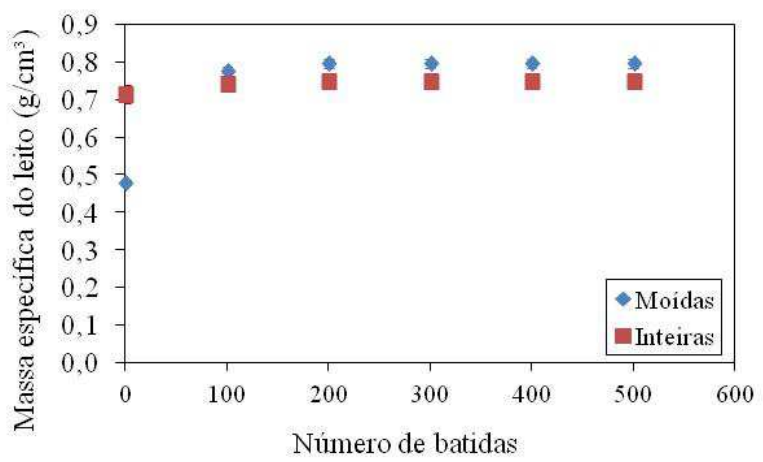

Fonte: Autor (2015).

As porosidades dos leitos aerado e compactado para as sementes de cevada moídas e inteiras foram obtidas por meio da Equação 7, conforme Tabela 1.

Tabela 1 - Porosidades dos leitos aerado e compactado para as sementes moídas e inteiras.

\begin{tabular}{lcc}
\cline { 2 - 3 } & \multicolumn{2}{c}{ Porosidade do leito (-) } \\
\cline { 2 - 3 } & Aerado & Compactado \\
\hline Moídas & $0,64 \pm 0,01$ & $0,45 \pm 0,02$ \\
Inteiras & $0,504 \pm 0,005$ & $0,480 \pm 0,005$ \\
\hline
\end{tabular}

Fonte: Autor (2015).

Conforme os resultados mostrados na Tabela 1, pode-se constatar que, a variação de porosidade para as sementes de cevada inteiras entre o leito aerado e compactado é muito pequena, em variação percentual não sendo maior que 5\%, menor quando comparada a de semente moída que foi próximo a $40 \%$.

Com base nisto, optou-se a utilização de sementes de cevada moída para avaliação dos efeitos da porosidade na condutividade térmica efetiva.

Outro fator importante é que, segundo Pietrobon (1988), a redução do tamanho de partículas o efeito da resistência de contato entre o meio poroso e a sonda.
Para a compressão com impactação a porosidade foi de $0,34 \pm 0,01$ para as sementes moídas. Sendo que, a partir de 100 impactos com a marreta emborrachada não houve mais variação da massa específica.

Após a compressão com a prensa hidráulica com uma força de aproximadamente 1,5 ton a porosidade foi de $0,26 \pm 0,01$.

Estes testes foram importantes na obtenção de informações complementares da metodologia de preparação dos leitos, para que posteriormente, as medidas de condutividade térmica fossem realizadas. Estes resultados forneceram parâmetros, como: o valor da porosidade para cada técnica, a força necessária e o número de impactos que eram necessários para volume constante.

Portanto, o objetivo inicial de obter diferentes porosidades de leito foi obtido. Assim sendo, os testes para a obtenção da condutividade térmica efetiva puderam ser realizados.

\subsection{Condutividade Térmica Efetiva}

A Figura 4 mostra a condutividade térmica efetiva em função da porosidade do leito das sementes de cevada moídas.

Figura 4 - Condutividade térmica efetiva em função da porosidade do leito de sementes de cevada em pó.

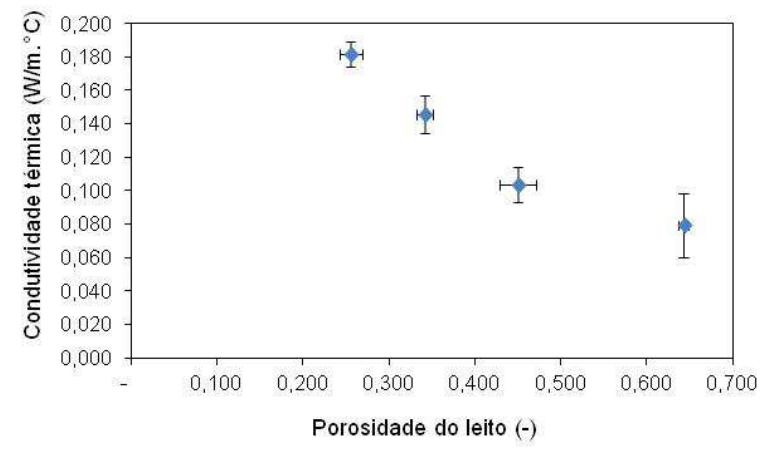

Fonte: Autor (2015).

Conforme mostra a Figura 4, pode-se constatar que para valores menores que 0,6 de 
porosidade, há uma relação linear da condutividade térmica efetiva com a porosidade.

Com a maior redução na porosidade entre o leito aerado $(0,64 \pm 0,01)$ e compactado $(0,45 \pm 0,02)$ não houve uma aumento significativo na condutividade térmica, pois entre estes dois métodos apenas uma reorganização das partículas provocou a redução da porosidade. Porém, nenhuma força foi aplicada para aumentar o contato entre as partículas.

Ou seja, para o leito aerado as partículas estavam dispostas como foram dispendidas no meio. Para o leito compactado, foram realizados os impactos em queda livre promovendo a reorganização das partículas de forma que estas, preencheram os espaços vazios, com isto, reduzindo a porosidade.

Quando as técnicas de compressão, com impactos com a marreta emborrachada ou com a prensa hidraulica são avaliadas. Observa-se que para estas há uma força normal aplicada sobre a superfície do leito, realizando sobre o meio poroso, forçando as partículas se aproximarem e por conquência aumentando os pontos de contato dentro do leito.

Por meio disto, pode-se inferir por meio do resultado apresentado na Figura 3, a influência do contato das partículas no meio poroso sobre a condutividade térmica efetiva.

Com base na Figura 4, pode-se observar que o desvio padrão da condutividade térmica aumenta com o aumento da porosidade do leito, isto pode ter ocorrido, devido a condutividade térmica ter reduzido com a porosidade, ou seja, reduzindo o fluxo de calor pelo meio poroso.

Desta forma, a maior parte do calor gerado pela resistência elétrica ficou acumulada no centro do meio poroso.

Assim sendo, para maiores porosidades os desvios causados pela instabilidade da fonte de energia elétrica que fornecia o calor e o contato do meio poroso e a sonda tiveram maior influência sobre as temperaturas medidas no centro do meio poroso, aumentando os desvios padrões na medida da condutividade térmica.

Outro ponto que justifica este aumento no desvio padrão é a estrutura do leito. Os poros maiores tornam-se mais difícil de reproduzir, aumentando as variações entre os experimentos.

No caso do leito aerado há uma maior quantidade de poros, e consequentemente possíveis vibrações e impactos podem alterar esta estrutura. Ou seja, a estrutura do leito aerado era extremamente instável, dificultando a reprodução da estrutura e a continuidade desta formação estrutural durante os testes de condutividade térmica.

Para a análise destes possíveis problemas, testes das características físicas do meio poroso ao longo da altura do leito foram realizados.

\subsection{Características Físicas ao Longo da Altura do Meio Poroso}

$\mathrm{Na}$ Figura 5, a seguir, têm-se os resultados de massa específica do leito em relação a altura do leito e das quatro técnicas de preparação do meio poroso.

De acordo com o que pode ser visto na Figura 5, pode se constatar que na região da base, para todas as formas de empacotamento a massa específica foi maior, o que se deve ao efeito da propagação de força. As camadas superiores do meio poroso aplicavam uma força sobre as camadas inferiores, compactando mais o pó presente na região da base, tornando essa região mais densa.

Além disto, na Figura 5 pode ser visto que a massa específica varia conforme a altura do leito, sendo esta diferença maior o empacotamento aerado (primeira). Onde pode ser observado que há uma variação significativa entre o topo, meio e base. Isto se justifica devido à junção de dois efeitos, o da propagação da força entre as camadas do meio poroso e o da instabilidade de matrizes 
muito porosa, que ambos já foram discutidos anteriormente (MATA e DUARTE, 2002).

Figura 5 - Massa específica do leito em relação as quatro formas de empacotamento, comparado entre as alturas de leito.

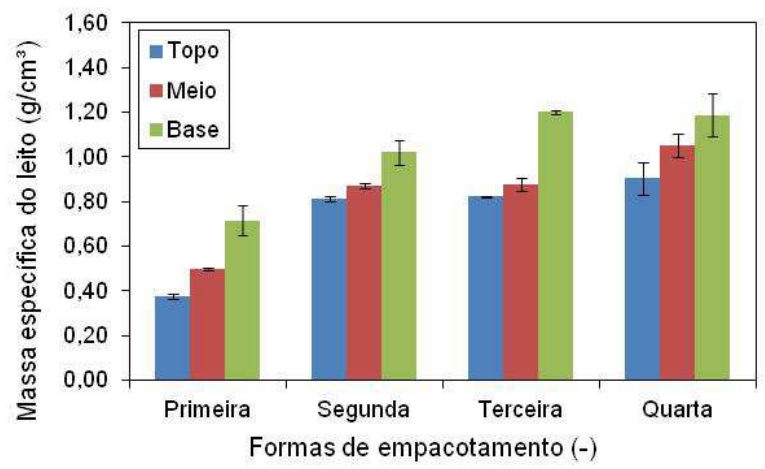

Fonte: Autor (2015).

Para a segunda e terceira técnica de empacotamento do leito, valores mais próximos do meio e do topo são observados.

Estas duas formas de empacotamento, diferenciam-se das demais, devido a utilização de impactos durante o processo de preparação do meio poroso. Por meio disto, pode se inferir que, a homogeneidade da massa específica nas camadas superiores se deve a propagação da força por meio de ondas longitudinais (KARAGIOZOCA e ALVES, 2014).

Para a quarta técnica de empacotamento existe a variação entre as três regiões, mas a diferença entre as médias da massa específica estão próximas ao desvio em comparação as demais formas de empacotamento.

Analisando de forma geral, pode-se constatar que, quanto menor a porosidade, mais próxima a massa específica do leito está da massa específica das partículas, com isto, reduzindo as variações ao longo da altura do meio poroso, devido a aproximação as condições limites para a estrutura da matriz porosa.

A Figura 6 mostra os mesmo resultados da Figura 5, mas com a possibilidade de comparar entre as formas de empacotamento, a massa específica para cada região.
Figura 6 - Massa específica do leito em relação as alturas de leito, comparado entre as quatro formas de empacotamento.

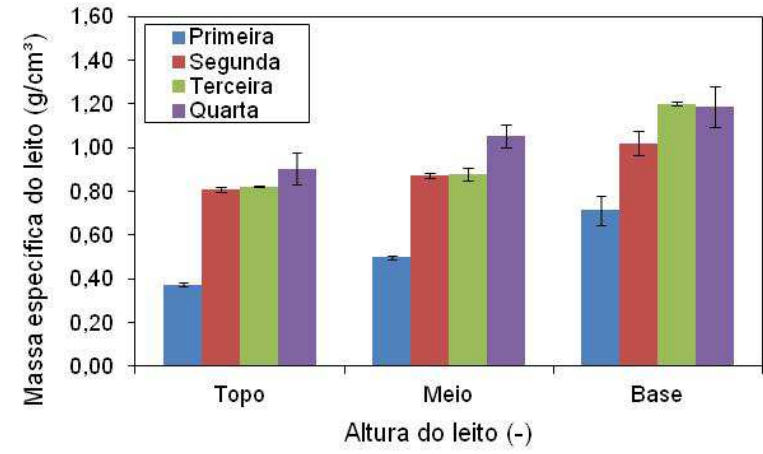

Fonte: Autor (2015).

A Figura 6 permite, novamente, a inferência que o contato foi mais influente do que a porosidade para os testes de condutividade térmica.

A massa específica do meio para a segunda e terceira técnica de empacotamento não apresentam variações significativas. Porém, observa-se uma variação significativa da condutividade térmica entre essas duas técnicas na Figura 4.

Ou seja, se o termopar para a medida da temperatura está nessa região do meio poroso, a variação da condutividade térmica pode estar relacionada ao aumento de contato entre as partículas da terceira para a quarta metodologia de empacotamento.

Na Figura 7 estão dispostos os dados de umidade em base úmida para as diferentes formas de empacotamento, comparado entre as alturas de leito.

De acordo com a Figura 7, a primeira e quarta forma de empacotamento, apresentaram valores mais homogêneos de umidade.

Para a quarta forma de empacotamento a condutividade térmica foi maior, onde o teste de condutividade não apresentou variações tão significativas de temperatura no centro, quanto para as outras técnicas de empacotamento, pois o meio poroso proporcionava um alto fluxo de calor. 
Figura 7 - Umidade em base úmida das sementes em relação formas de empacotamento, comparadas entre as alturas de leito.

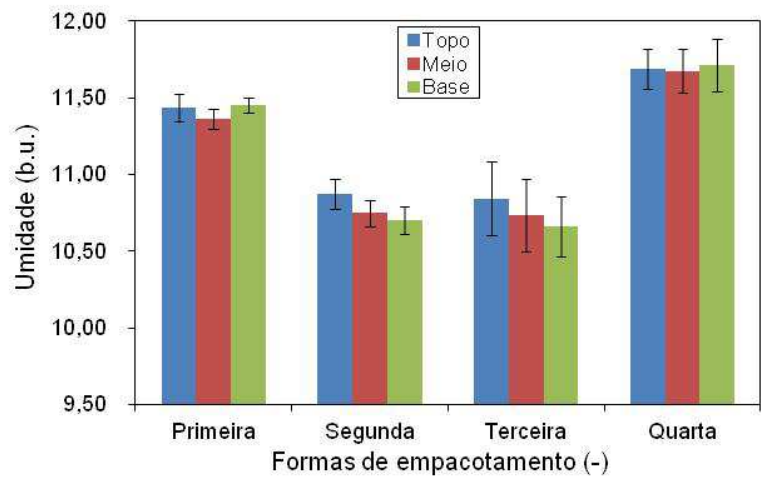

Fonte: Autor (2015).

Enquanto que para maiores porosidade ou menor condutividade térmica (primeira forma de empactamento) teve-se maior gradiente radial de temperatura. Todavia o teste foi mais rápido, sendo que a quantidade de calor total fornecida ao meio poroso foi menor.

Para a segunda e terceira forma de empacotamento houve uma tendência de aumentar a umidade média ao longo da altura do leito, porém a diferença entre as médias são menores do que os desvios, mostrando que a diferença não é significativa. Se calcularmos a diferença de umidade entre o topo e a base, a variação não foi maior do que $0,18 \%$.

Entre as quatro formas de empacotamento, foram observadas variações de umidade, porém os erros percentuais não foram maiores do que $8 \%$, ou seja, menores que os erros comumente aceitos na engenharia.

A Figura 8 mostra a distribuição granulométrica, através da fração mássica retida em cada peneira para as 3 alturas de leito para os experimentos com leito aerado.

Com base na Figura 8, pode se constatar que a distribuição granulométrica foi a mesma para as alturas de leito e o mesmo foi observado para as outras formas de empacotamento.
Figura 8 - Frações mássicas retidas em relação as aberturas de malha das peneiras, para os experimentos com leito aerado.

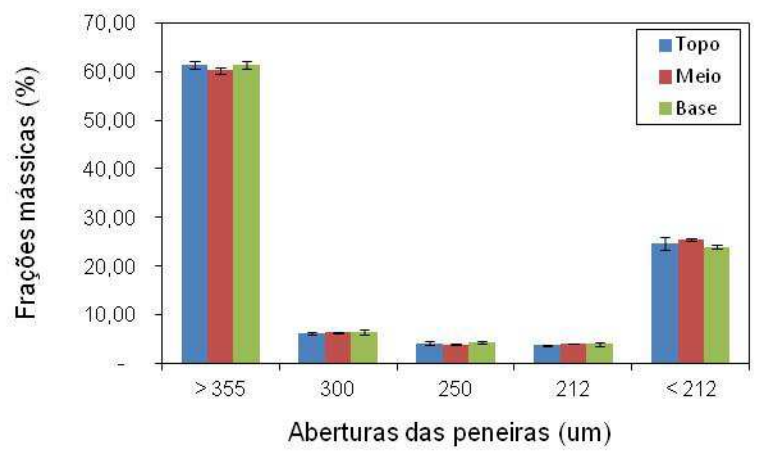

Fonte: Autor (2015).

Observa-se que, a distribuição granulométrica mostra dois valores significativamente maiores de retenção de massa no fundo das peneiras e no topo. Isto pode estar relacionado com a anatomia vegetal das sementes de cevada, pois a moagem das sementes continha dois materiais com características físicas e mecânicas distintas.

No topo do conjunto de peneiras foram concentradas as partículas que majoritariamente foram formadas da moagem da casca, enquanto que, no fundo do conjunto de peneiras foram concentradas partículas formadas da moagem do endosperma das sementes.

Isto pode ser constatado, devido a cor mais amarelada da massa retida na peneira do topo, como a cor da casca destas sementes e da cor mais clara, tendendo ao branco da massa retida no fundo das peneiras, como a cor do endosperma.

\section{CONCLUSÕES}

Com base nos resultados e discussões realizados anteriormente, pode-se concluir que:

- As formas de empacotamento forneceram diferentes massas específicas de leito; 
As diferentes formas de empacotamento mostraram que, a variação da porosidade não teve influência predominante na variação da condutividade térmica, podendo ter outros mecanismos envolvidos, como o contato;

- Ocorreram variações na massa específica ao longo da altura do leito devido ao efeito da propagação da força;

- Quanto mais próximo a massa específica do leito foi da massa específica das partículas, menor a variação longitudinal desta propriedade no meio poroso para estas técnicas de empacotamento estudadas;

- As características físicas, como umidade em base úmida e distribuição granulométrica não apresentaram variações ao longo do leito para estas técnicas de empacotamento e método de medida de condutividade térmica, e

- A distribuição granulométrica do pó da semente de cevada teve maiores valores de massa retida no topo e na base do conjunto de peneiras, que estão relacionados aos produtos da moagem da casca e do endosperma, respectivamente.

\section{NOMENCLATURA}

$\begin{array}{llr}\mathrm{a} & \text { Raio da sonda. } & (\mathrm{m}) \\ \mathrm{c} & \mathrm{c}=\exp (\gamma) & (-) \\ \mathrm{K}_{\mathrm{eff}} & \text { Condutividade térmica efetiva. } & \left(\mathrm{W} / \mathrm{m}^{\circ} \mathrm{C}\right) \\ \mathrm{m}_{\mathrm{s}} & \text { Massa seca. } & (\mathrm{g}) \\ \mathrm{m}_{\mathrm{u}} & \text { Massa úmida. } & (\mathrm{g}) \\ \mathrm{q} & \text { Calor por unidade de } & \\ & \text { comprimento da sonda. } & (\mathrm{W} / \mathrm{m}) \\ \mathrm{r} & \text { Raio } & (\mathrm{m}) \\ \mathrm{T} & \text { Temperatura. } & \left({ }^{\circ} \mathrm{C}\right) \\ \mathrm{T}_{\mathrm{o}} & \text { Temperatura inicial } & \left({ }^{\circ} \mathrm{C}\right) \\ & & \\ \alpha & \text { Difusividade térmica. } & \left(\mathrm{m}^{2} / \mathrm{s}\right) \\ \gamma & \text { Constante de Euler, } & (-) \\ & \gamma=0,5772156649 \ldots & (-) \\ \varepsilon_{\mathrm{L}} & \text { Porosidade do leito. } & \left(\mathrm{kg} / \mathrm{m}^{3}\right) \\ \rho_{\mathrm{L}} & \text { Massa específica do leito. } & \left(\mathrm{kg} / \mathrm{m}^{3}\right) \\ \rho_{\mathrm{R}} & \text { Massa específica real. } & \\ \mathrm{R} & \text { Real, sem volume dos poros. } & \end{array}$

\section{REFERÊNCIAS}

CARSLAW, H. S.; JAEGER, J. C. Conduction of heat in solids. 5. ed. Londres: Clarendon Press, 1959. p. 517.

CARVALHO, N. M.; NAKAGAWA, J. Sementes: ciência, tecnologia e produção. Campinas: Fundação Cargil, 1980. p. 326.

HOLMAN, J. P. Transferência de calor. São Paulo: McGraw-Hill do Brasil, 1983, 639 p.

KARAGIOZOVA, D; ALVES, M. Compaction of a double-layered metal foam block impacting a rigid wall. International Journal of solids and structures, v. 51, n. 13, p2423-2438, 2014.

MATA, M. E. R. M. C.; DUARTE, M. E. M. Porosidade intergranular de produtos agrícolas. Revista Brasileira de Produtos Agroindustriais, Campina Grande, PB, v. 4, n. 1, p. 79-93, 2002.

PERAZZINI, H. Secagem de solidos porosos granulares. 2014. 190p. (Doutorado em Engenharia Química) - Universidade Federal de São Carlos, São Carlos, 2014.

PIETROBON, C. L. R. Desenvolvimento de sistemas para a determinação da condutividade térmica. 1988. 122p. (Mestrado em Engenharia Química) Universidade Federal de São Calor, São Carlos, 1988.

\section{AGRADECIMENTOS}

Ao CNPq e CAPES pelo auxílio financeiro. 